Ann. Génét. Sél. anim., I969, 1 (4), 315-336.

REVUE BIBLIOGRAPHIQUE

\title{
LES CHROMOSOMES DES SUIFORMES
}

\author{
Françoise HULOT \\ Station centrale de Génétique animale, \\ Centre national de Recherches zootechniques, 78 -Jouy-en-Josas \\ Institut national de la Recherche agronomique
}

\begin{abstract}
RÉSUMÉ
Le caryotype de Sus scrofa domesticus est caractérisé par 19 paires de chromosomes dont la morphologie permet un classement précis.

Les tests cytologiques utilisés pour la détermination rapide du sexe (chromatine de Barr, appendices nucléaires) donnent des résultats variables selon les tissus utilisés.

Les recherches portant sur les anomalies sont peu nombreuses. Elles concernent la léthalité embryonnaire ( $3 n, 4 n, 2 n / 3 n$, délétion), les troubles de la fertilité chez le verrat (translocation hétérozygote, spermatogenèse perturbée), l'intersexualité. Celle-ci, assez fréquente, a fait l'objet de récentes recherches caryologiques. Les intersexués présentent des formules chromosomiques variées : XX (masculinisation par un gène d'intersexualité autosomal et récessif), XY (syndrome dit du " testicule féminisant "), XXY et XXXY / XXY (syndromes homologues à celui de Klinefelter), $\mathrm{XX} / \mathrm{XY}$ (freemartinisme).

Le nombre chromosomique de quelques autres Suiformes a été défini : Sus scrofa $L$. $(2 n=36$ ou 37) variations attribuées à un polymorphisme chromosomique, Dicotyles tajacu et angulatus $(2 n=30)$, Hippopotamus amphibius $(2 n=36)$.
\end{abstract}

\section{INTRODUCTION}

Les études chromosomiques des Suiformes se sont développées parallèlement à celles des Ruminants (HULOT et LAUVERGNE, r967) depuis le début du $\mathrm{xx}^{\mathrm{e}}$ siècle. La similitude de leurs progressions est due à l'amélioration générale des méthodes d'investigations. Bien que quelques auteurs se soient intéressés aux espèces sauvages du genre Sus, aux Dicotyles et même à la famille des Hippopotamidae, seul le Porc domestique, Sus scrofa domesticus $L$. a fait l'objet de recherches approfondies (cf. tabl. I pour classification). 
TABLEAU I

Classification des Suiformes selon FrechkoP (I955)

Ordre des Artiodactyles

Sous-ordre des Suiformes

I. Famille $=$ Hippopotamidae

$$
\text { Genre }=\underset{\text { Choeropsis }}{\text { Hippopotamus }} \quad \text { espèce }=\underset{\text { liberiensis }}{\text { amphibius }}
$$

2. Famille $=$ Suidae

Sous-famille des Suinae

Genre $=$ Sus

$$
\begin{aligned}
\text { Genre }= & \text { Porcula } \\
& \text { Barbirussa } \\
& \text { Potamochoerus } \\
& \text { Hylochoerus } \\
& \text { Phacochoerus }
\end{aligned}
$$

Sous-famille des Dicotylinae

$$
\text { Genre }=\text { Dicotyles }
$$

Genre $=$ Tayassu

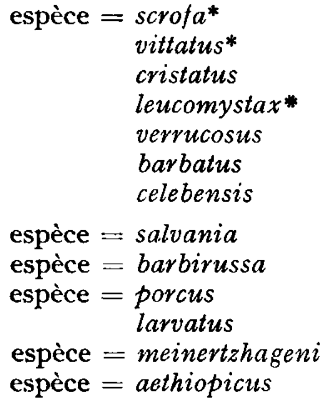

* İspèces étudiées.

FAMILLE DES SUIDAE

SOUS-FAMILLE DES Suinae

A. - Sus scrofa domesticus $L$.

\section{I. - Les chromosomes}

I. Évolution des techniques caryologiques.

De I9I3 à 1950 , les chercheurs utilisent les procédés classiques de 1'histologie; ceux-ci ont l'inconvénient de réduire l'investigation aux tissus embryonnaires ou testiculaires qui, seuls, présentent spontanément un nombre suffisant de divisions cellulaires. En outre, cette technique nécessite des coupes sériées et la reconstitution des figures chromosomiques dans l'espace. 
De I950 à I960, la technique du " squash " supplante les procédés histologiques. Le testicule est toujours utilisé mais les tubes séminifères sont dilacérés. Par sa rapidité d'exécution et la qualité supérieure des préparations, le " squash " marque déjà un net progrès.

A partir de r960, l'utilisation des cultures cellulaires ouvre des possibilités nouvelles pour l'étude des chromosomes de tissus somatiques variés.

Le détail de l'ensemble de ces techniques est reporté dans le tableau 2; celui-ci est établi dans un ordre chronologique qui permet de dégager les principales étapes.

\section{TABLEAU 2}

Caryotype du Porc domestique (Sus scrofa domesticus) Ívolution chronologique des techniques utilisées

\begin{tabular}{|c|c|c|c|c|}
\hline Auteurs & Tissus & Techniques & Fixation & Coloration \\
\hline WODSEDALEK, I9I3 & $\begin{array}{l}\text { Testicule } \\
\text { Ovaire } \\
\text { Mésonéphros } \\
\text { embryonnaire }\end{array}$ & $\begin{array}{l}\text { Coupes } \\
\text { paraffine }\end{array}$ & $\begin{array}{l}\text { Bouin-Zenker } \\
\text { Tellyesnicky } \\
\text { Acide acétique } \\
\text { Flemming }\end{array}$ & $\begin{array}{l}\text { Hématoxyline de } \\
\text { Heidenhain + } \\
\text { Fuchsine acide } \\
\text { Hématoxyline } \\
\text { Delafield +- } \\
\text { éosine }\end{array}$ \\
\hline HANCE, I917-19I8 & $\begin{array}{l}\text { Testicule } \\
\text { Amnios }\end{array}$ & $\begin{array}{l}\text { Coupes } \\
\text { paraffine }\end{array}$ & Flemming & $\begin{array}{l}\text { Alun de fer } \\
\text { Hématoxyline }\end{array}$ \\
\hline KRALLINGER, I93 I & Testicule & $\begin{array}{l}\text { Coupes } \\
\text { paraffine }\end{array}$ & & \\
\hline BRYDEN, I933. . & Testicule & $\begin{array}{l}\text { Coupes } \\
\text { paraffine }\end{array}$ & $\begin{array}{l}2 \mathrm{BD} ; 2 \mathrm{BDE} \text {, } \\
2 \mathrm{BD} \text { et Carnoy } \\
\text { Flemming }\end{array}$ & Violet de gentiane \\
\hline $\begin{array}{c}\text { CREW et KOLIER, } \\
\text { I939 } \\
\end{array}$ & Testicule & $\begin{array}{l}\text { Coupes } \\
\text { paraffine }\end{array}$ & $\begin{array}{l}\text { Minouchi- } \\
\text { Champy }\end{array}$ & Violet de gentiane \\
\hline MAKINO, I944a & Testicule & $\begin{array}{l}\text { Coupes } \\
\text { paraffine }\end{array}$ & $\begin{array}{l}\text { Champy } \\
\text { Flemming }\end{array}$ & $\begin{array}{c}\text { Hématoxyline de } \\
\text { Heidenhaim }+ \\
\text { vert lumière }\end{array}$ \\
\hline MELANDER, I95I. & Testicule & Squash & Éthanol acétique & Feulgen \\
\hline SACHS, 1954. & Testicule & Squash & Éthanol acétique & Feulgen \\
\hline $\begin{array}{c}\text { SPALDING et BERRY, } \\
\text { I956 . . . . . }\end{array}$ & Testicule & Squash & Éthanol acétique & Carmin acétique \\
\hline Aparicio RUIZ, I960 & Testicule & $\begin{array}{l}\text { Coupes } \\
\text { paraffine } \\
\text { Squash }\end{array}$ & $\begin{array}{l}\text { Liquide de Nava- } \\
\text { chine } \\
\text { Méthanol } \\
\text { Carnoy }\end{array}$ & $\begin{array}{l}\text { Hématoxyline de } \\
\text { Heidenhain } \\
\text { Orcéine acétique } \\
\text { Giemsa } \\
\text { Feulgen }\end{array}$ \\
\hline RUDDLE, I96I-I 964. & $\begin{array}{l}\text { Rein } \\
\text { Rein fœtal }\end{array}$ & Culture & & Orcéine acétique \\
\hline
\end{tabular}


TABLEAU 2 (suite)

Caryotype du Porc domestique (Sus scrofa domesticus)

Évolution chronologique des techniques utilisées

\begin{tabular}{|c|c|c|c|c|}
\hline Auteurs & Tissus & Techniques & Fixation & Coloration \\
\hline $\begin{array}{l}\text { MAKINO, SASAKI, SO- } \\
\text { FUNI, ISHIKAWA, } \\
\text { I962. } . . .\end{array}$ & Leucocytes & Culture & & Dahlia acétique \\
\hline $\begin{array}{ccc}\text { GIMENEZ } & \text { MARTIN, } \\
\text { LOPEZ } & \text { SAEZ } & \text { et } \\
\text { MONGE, } & \text { I963 }\end{array}$ & Moelle osseuse & $\begin{array}{l}\text { Culture } \\
\text { (court terme) }\end{array}$ & & \\
\hline $\begin{array}{l}\text { MC CONNEL, FEICH- } \\
\text { HEIMER et GIL- } \\
\text { MORE, I } 963 .\end{array}$ & Leucocytes & Culture & Méthanol acétique & Feulgen \\
\hline $\begin{array}{l}\text { HENRICSON et } \\
\text { BÄCKSTRÖM, I963a } \\
\text { I } 964 a . \cdot \cdot \cdot \cdot \cdot\end{array}$ & Testicule & $\begin{array}{l}\text { Coupes } \\
\text { paraffine } \\
\text { Squash }\end{array}$ & Éthanol acétique & $\begin{array}{l}\text { Hématoxyline de } \\
\text { Gomori } \\
\text { Orcéine }\end{array}$ \\
\hline STONE, I963. . . & Leucocytes & Culture & & Soudan Black B \\
\hline $\begin{array}{l}\text { ANTONIO, r964, An- } \\
\text { TONIO et CASTRUC- } \\
\text { CI, I964. . . . }\end{array}$ & $\begin{array}{l}\text { Leucocytes } \\
\text { Rein }\end{array}$ & Culture & Méthanol acétique & Orcéine acétique \\
\hline $\begin{array}{r}\text { BRUYÈRE, LAGNEAU } \\
\text { ET MEWISSEN I965 }\end{array}$ & $\begin{array}{l}\text { Sang total ou } \\
\text { Leucocytes }\end{array}$ & Culture & Méthanol acétique & Orcéine acétique \\
\hline Evans, $1965 \cdot \cdots$ & Sang total & $\begin{array}{l}\text { Culture } \\
\text { Autoradiographie }\end{array}$ & Ethanol acétique & Orcéine acétique \\
\hline HARD et EISEN, I965 & $\begin{array}{l}\text { Leucocytes } \\
\text { Fibroblastes }\end{array}$ & Culture & & Giemsa \\
\hline $\begin{array}{l}\text { GERNEKE, I964a- } \\
\text { I967 . . . . . }\end{array}$ & Moelle osseuse & $\begin{array}{l}\text { Culture } \\
\text { (court terme) }\end{array}$ & Méthanol acétique & $\begin{array}{l}\text { May-Grünwald } \\
\text { Giemsa }\end{array}$ \\
\hline BRUYÈRE, I966 . . & Leucocytes & $\begin{array}{l}\text { Culture } \\
\text { Autoradiographie }\end{array}$ & & Orcéine acétique \\
\hline $\begin{array}{l}\text { MC FEE, BANNER et } \\
\text { Rary, 1966... }\end{array}$ & Leucocytes & Culture & Éthanol acétique & Orcéine acétique \\
\hline MCFEELY, I966 . . & Blastula & $\begin{array}{l}\text { Cuiture } \\
\text { (court terme) }\end{array}$ & Méthanol acétique & Giemsa \\
\hline $\begin{array}{l}\text { GIMENEZ MARTIN, } \\
\text { LOPEZ SAEZ, I966 }\end{array}$ & Moelle & $\begin{array}{l}\text { Culture } \\
\text { (court terme) }\end{array}$ & Éthanol acétique & Orcéine acétique \\
\hline VoGr, I967 . . . . & Leucocytes & Culture & Éthanol acétique & Orcéine acétique \\
\hline $\begin{array}{r}\text { CORNEFER'T JENSEN, } \\
\text { HARE et ABT, r } 968\end{array}$ & Leucocytes & $\begin{array}{l}\text { Culture } \\
\text { Autoradiographie }\end{array}$ & & Giemsa \\
\hline
\end{tabular}




\section{Le nombre de chromosomes.}

Bien que WodSEDALEK (I9I3), ait trouvé un nombre diploïde de I 8 chromosomes chez le mâle et 20 chez la femelle, les auteurs suivants s'accordent pour reconnaître au nombre diploïde de l'espèce la valeur de 38 ou 40 (tabl. 3). Toutefois, HANCE, I 917 , attribue à la lignée germinale un nombre fixe de 40 chromosomes et à la lignée somatique un nombre variant entre 40 et 58 .

Pendant 30 ans, la polémique concernant le nombre chromosomique reste vive. Il faut attendre I 960 et l'utilisation des cultures pour que l'accord se réalise sur le chiffre définitif de 38 chromosomes et que la variabilité éventuelle des résultats obtenus soit imputée, non pas à des différences inter-raciales comme le pensait KRALLINGER (I93I) mais à des défauts de techniques.

Toutefois, une réserve semble devoir être faite en ce qui concerne une vieille race suédoise "Old Swedish" dans laquelle MELANDER (I95I) note un nombre diploïde de 30 chromosomes. Chez les Hybrides Yorkshire $\times$ Old Swedish, cet auteur trouve une gamme comprise entre 30 et 36 chromosomes alors que SACHS (I954) sur des animaux de même race et des hybrides similaires, établit un caryotype uniforme de 40 chromosomes.

\section{TABLEAU 3}

Étapes chronologiques de l'étude du nombre chromosomique $d u$ Porc domestique (Sus scrofa domesticus)

\begin{tabular}{|c|c|c|c|c|c|c|}
\hline Races & Tissus & $2 n$ & $\mathrm{x}$ & $Y$ & Auteurs & Dates \\
\hline Poland-China . & $\begin{array}{l}\text { Testicule } \\
\text { Mésonéphros } \\
\text { embryonnaire }\end{array}$ & $\begin{array}{l}\sigma=\mathbf{1} 8 \\
i=20\end{array}$ & ovale & 0 & WODSEDALEK & 1913 \\
\hline $\begin{array}{l}\text { Berkshire } \\
\text { Poland-China } \\
\text { Jersey-Red }\end{array}$ & $\begin{array}{l}\text { Amnios } \\
\text { Différents tissus } \\
\text { embryonnaires }\end{array}$ & $\begin{array}{l}40 \\
\grave{a} \\
58\end{array}$ & & & HANCE & $\begin{array}{l}1917 \\
\text { I91 }\end{array}$ \\
\hline $\begin{array}{l}\text { Race locale (All.) } \\
\text { Berkshire . . . }\end{array}$ & Testicule & $\begin{array}{l}38 \\
38\end{array}$ & long & $?$ & KRAL,IINGER & I93I \\
\hline $\begin{array}{l}\text { Large White. . } \\
\text { Yorkshire. . . }\end{array}$ & Testicule & 38 & $\begin{array}{l}\text { le }+ \\
\text { long }\end{array}$ & $\begin{array}{l}\text { le }+ \\
\text { petit }\end{array}$ & BRYDEN & ‘i933 \\
\hline $\begin{array}{l}\text { Race locale (Ail.). } \\
\text { Berkshire. . . }\end{array}$ & Testicule & $\begin{array}{l}38 \\
3^{8}\end{array}$ & & & HILLLEBRAND & 1936 \\
\hline Large White. . . & Testicule & 38 & $\begin{array}{l}\mathrm{ST} \\
\text { ou SM } \\
\text { moyen }\end{array}$ & $\begin{array}{l}\text { ST } \\
\text { ou } T\end{array}$ & CREW et KOLLER & $\begin{array}{l}\text { I938- } \\
\text { I939 }\end{array}$ \\
\hline $\begin{array}{l}\text { White Yorkshire } \\
\text { Race locale (Jap.) }\end{array}$ & Testicule & $\begin{array}{l}4^{\circ} \\
4^{\circ}\end{array}$ & $\begin{array}{l}\mathrm{T} \text { ou } \\
\mathrm{ST} \\
\text { long }\end{array}$ & $\begin{array}{l}\text { le }+ \\
\text { petit }\end{array}$ & MAKINO & $\begin{array}{c}\text { I944a, } b \text {, } \\
\text { I949- } \\
\text { I95I } \\
\text { I956 } \\
\end{array}$ \\
\hline $\begin{array}{l}\text { Yorkshire . } \\
\text { Old Swedish . } \\
\text { Hybride . . . }\end{array}$ & Testicule & $\left|\begin{array}{c}38 \\
30 \\
30 \text { à } 36\end{array}\right|$ & & & MÉI_ANDER & $195 \mathrm{I}$ \\
\hline
\end{tabular}


TABLEAU 3 (suite)

Étapes chronologiques de l'étude du nombre chromosomique du Porc domestique (Sus scrofa domesticus)

\begin{tabular}{|c|c|c|c|c|c|c|}
\hline Races & Tissus & $2 n$ & $\mathrm{x}$ & $\mathrm{Y}$ & Auteurs & Dates \\
\hline $\begin{array}{l}\text { Old Swedish } \\
\text { Old Sw } \times \text { York- } \\
\text { shire } . \times \text {. } . ~ \\
\text { Old Sw } \times \text { Large } \\
\text { White. } .\end{array}$ & Testicule & $\begin{array}{l}40 \\
40 \\
40\end{array}$ & & & SACHS & I954 \\
\hline $\begin{array}{l}\text { Chester White. } \\
\text { Poland China . } \\
\text { Duroc Jersey. . } \\
\text { Hampshire. . }\end{array}$ & Testicule & $\begin{array}{l}4^{\circ} \\
4^{\circ} \\
4^{\circ} \\
4^{\circ}\end{array}$ & long & petit & $\begin{array}{l}\text { SPALDING et } \\
\text { BERRY }\end{array}$ & 1956 \\
\hline $\begin{array}{c}\text { Rubia (race ibéri- } \\
\text { que). } . . .\end{array}$ & Testicule & $4^{\circ}$ & & & APARICIO RUIZ & I 960 \\
\hline Hampshire. . . & $\begin{array}{l}\text { Rein (lignée cel- } \\
\text { lules) } \\
\text { Leucocytes }\end{array}$ & 38 & $\begin{array}{l}\mathrm{SM}-\mathrm{M} \\
\text { moyen }\end{array}$ & $\begin{array}{c}\text { SM } \\
\text { petit }\end{array}$ & RUDDLE & I96II \\
\hline Yorkshire . & Leucocytes & $3^{8}$ & $\begin{array}{c}\mathrm{SM} \\
\text { moyen }\end{array}$ & $\underset{\text { petit }}{\mathrm{M} \mathrm{le}+}$ & $\begin{array}{l}\text { MaKINO, SASAKI, } \\
\text { SOFUNI, ISHI- } \\
\text { KAWA } \\
\end{array}$ & I962 \\
\hline Large White. & Moelle & 38 & $\begin{array}{l}\mathrm{SM}-\mathrm{M} \\
\text { moyen }\end{array}$ & $\begin{array}{l}\text { SM - M } \\
\text { le }+ \\
\text { petit }\end{array}$ & $\begin{array}{l}\text { GIMENEZ-MARTIN } \\
\text { LOPEZ-SAEZ } \\
\text { IDEM + MONGE } \\
\end{array}$ & $\begin{array}{l}1962 \\
1963 \\
\end{array}$ \\
\hline Swedish Landrace & Testicule & $3^{8}$ & $\begin{array}{c}\mathrm{SM} \\
\text { moyen }\end{array}$ & $\begin{array}{l}\text { SM } \\
\text { petit }\end{array}$ & $\begin{array}{l}\text { HENRICSON et } \\
\text { BäCKSTRÖM }\end{array}$ & $\begin{array}{l}1963 a \\
1964 a\end{array}$ \\
\hline $\begin{array}{l}\text { Yorkshire . . . } \\
\text { Landrace } \\
\text { Poland China } \\
\text { Berkshire . } \\
\text { Duroc } \\
\text { Hampshire. } . \\
\end{array}$ & Leucocytes & $\begin{array}{l}38 \\
38 \\
38 \\
38 \\
38 \\
38\end{array}$ & $\begin{array}{c}\mathrm{SM} \\
\text { moyen }\end{array}$ & $\begin{array}{c}\text { M } \\
\text { petit }\end{array}$ & $\begin{array}{l}\text { MCCONNEL, } \\
\text { FECHHEIMER et } \\
\text { GILMORE }\end{array}$ & 1963 \\
\hline Hampshire. . . & Leucocytes & 38 & $\begin{array}{c}\mathrm{ST} \\
\text { moyen }\end{array}$ & $\begin{array}{l}\text { SM } \\
\text { long }\end{array}$ & STONE & 1963 \\
\hline Reggiana . . & $\begin{array}{l}\text { Cellules rénales } \\
\text { Leucocytes }\end{array}$ & 38 & $\begin{array}{c}\text { SM } \\
\text { moyen }\end{array}$ & $\begin{array}{c}\text { SM } \\
\text { petit }\end{array}$ & $\begin{array}{l}\text { ANTONIO } \\
\text { ANTONIO et CAS- } \\
\text { TRUCCI }\end{array}$ & $\begin{array}{l}1964 \\
1964\end{array}$ \\
\hline Large White. . & Moelle osseuse & $3^{8}$ & $\begin{array}{c}\mathrm{M} \\
\text { moyen }\end{array}$ & $\begin{array}{c}\text { M le }+ \\
\text { petit }\end{array}$ & GERNEKE & $\begin{array}{l}1964 a \\
1967\end{array}$ \\
\hline $\begin{array}{l}\text { Yorkshire } . \\
\text { Landrace } \times \text { Minne- } \\
\text { sota Black. . }\end{array}$ & $\begin{array}{l}\text { Lencocytes } \\
\text { Fibroblastes }\end{array}$ & $3^{8}$ & $\begin{array}{c}\mathrm{M} \\
\text { moyen }\end{array}$ & $\underset{\text { petit }}{\mathrm{M} \mathrm{le}+}$ & HARD et EISEN & I965 \\
\hline \multirow[t]{2}{*}{$\begin{array}{l}\text { Yorkshire . . } \\
\text { Roja Extremena }\end{array}$} & $\begin{array}{l}\text { Leucocytes } \\
\text { Fibroblastes }\end{array}$ & 38 & $\begin{array}{c}\mathrm{SM} \\
\text { moyen }\end{array}$ & $\begin{array}{c}\mathrm{M} \\
\text { petit }\end{array}$ & $\begin{array}{l}\text { GIMENEZ-MARTIN } \\
\text { LOPEZ SAEZ }\end{array}$ & I.966 \\
\hline & Leucocytes & 38 & & & LODJA & I966 \\
\hline Pittman-Moore & Leucocytes & $3^{8}$ & $\begin{array}{c}\mathrm{SM} \\
\text { moyen }\end{array}$ & $\underset{\text { petit }}{\mathrm{M}}$ & $\begin{array}{l}\text { MCFEE, BANNER } \\
\text { et RARY }\end{array}$ & 1966 \\
\hline
\end{tabular}


TABLEAO 3 (suite)

Etapes chronologiques de l'étude du nombre chromosomique du Porc domestique (Sus scrofa domesticus)

\begin{tabular}{|c|c|c|c|c|c|c|}
\hline Races & Tissus & $2 n$ & $\mathbf{x}$ & $\mathrm{Y}$ & Auteurs & Dates \\
\hline Yorkshire & Blastocytes & $3^{8}$ & $\begin{array}{c}\text { SM } \\
\text { moyen }\end{array}$ & $\underset{\text { petit }}{\mathbf{M}}$ & MCFEEL, Y & I966 \\
\hline Large White & $\begin{array}{l}\text { Leucocytes } \\
\text { Tissu embryon- } \\
\text { naire }\end{array}$ & $3^{8}$ & $\begin{array}{c}\text { SM } \\
\text { moyen }\end{array}$ & $\begin{array}{c}\mathbf{M} \\
\text { petit }\end{array}$ & $\begin{array}{r}\text { BOMSEL-HELM- } \\
\text { REICHI }\end{array}$ & I967 \\
\hline Hampshire. . & Leucocytes & $3^{8}$ & $\begin{array}{c}\text { SM } \\
\text { moyen }\end{array}$ & $\underset{\text { petit }}{\mathbf{M}}$ & VoG'r & г967 \\
\hline $\begin{array}{l}\text { Hampshire. . } \\
\text { Yorkshire . }\end{array}$ & Leucocytes & $3^{8}$ & $\begin{array}{c}\mathrm{SM} \\
\text { moyen }\end{array}$ & $\begin{array}{c}\mathrm{M} \\
\text { petit }\end{array}$ & $\begin{array}{l}\text { CORNEFERT- } \\
\text { JENSEN, HARE } \\
\text { et ABT }\end{array}$ & I968 \\
\hline Légende: $\begin{array}{r}\mathbf{S T}= \\
\mathbf{S M}= \\
\mathbf{M}= \\
\mathrm{T}=\end{array}$ & $\begin{array}{l}=\text { subtélocentrique } \\
=\text { submédian } \\
=\text { médian } \\
=\text { télocentrique. }\end{array}$ & & & & & \\
\hline
\end{tabular}

3. Caryotypes.

Outre l'observation subjective de la morphologie des chromosomes, des techniques biométriques ont été appliquées, tendant à caractériser un chromosome ou un groupe de chromosomes par des mesures de longueur, des index centromériques et à leur attribuer des paramètres statistiques (HANCE, I9I7; MCCONNEI, et al., I963; ANTONIo, I964; RUDDLE, I964; CORNEFERT-JENSEN et al., I968). La technique histo-autoradiographique utilisant 1'incorporation de la thymidine tritiée facilite l'identification de 1'un des $\mathrm{X}$ qui, du fait de sa réplication tardive, subit un marquage radioactif électif (Evans, I965; BRUYìrE, I966; CORNEFERTJENSEN et al., I968).

Les interprétations caryologiques des auteurs postérieurs à I960 seront seules envisagées ici car elles sont le résultat d'analyse de figures métaphasiques de bonne qualité.

Si l'accord semble réalisé sur certains ensembles de chromosomes, il n'existe pas, à l'heure actuelle, un idiogramme de référence comme chez les humains.

a) Les autosomes. - Les divers schémas proposés répartissent les chromosomes en 2 groupes (fig. $\mathrm{r}$ ).

Le I $^{\text {er }}$ groupe, composé de $\mathrm{I} 2$ paires à centromère plus ou moins médian ou submédian, comprend 3 sous-groupes :

I paire de grands chromosomes à centromère submédian, reconnue par tous!les auteurs ( $\left.n^{\circ} \mathrm{r}\right)$;

9 paires à centromère submédian, médian ou subtélocentrique, dont le classement est délicat et encore controversé (nos $2,3,4,5,6,7,8,9$, 10). 


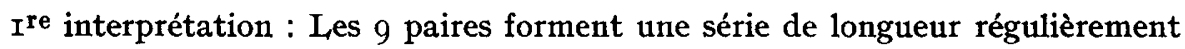
décroissante (Makino et al., I962; McConnel et al., I963; CASTruccr et ANTonio, I964; HENRICSON et BÄCKSTRÖM, I963a, I964a; HARD et EISEN, I965; LODJA, I966; BoMSEL-HELMREICH, I967). L'appariement des chromosomes en couples est rendu possible par l'examen soigneux de la position du centromère.

$2^{\mathrm{e}}$ interprétation : Les 9 paires sont scindées en 2 séries : 4 paires +5 paires (GIMENEZ-MARTin et al., I962; StONE, I963; GERNEKE, I964a), ou en 3 séries (GIMENEZ-MARTiN, Ig66).

$3^{\mathrm{e}}$ interprétation : RUDDLE (1964) s'appuie sur des données biométriques pour répartir ces 9 paires en 3 séries :

la I $^{\text {re }}$ formée par 2 paires de grande longueur et aettement submétacentrique ;

la $2^{\mathrm{e}}$ composée de $\mathrm{I} 2$ chromosomes presque métacentriques de taille régulièrement décroissante. MCFEE et al. (I966) et VoGT (1967) précisent ce schéma en les appariant;

la $3^{\mathbf{e}}$ est représentée par la paire $\mathbf{n}^{\mathbf{0}}$ Io qui est caractérisée par une constriction au niveau du centromère. MCFEELY et HARE (I966) 1'intègre dans la $2^{\mathrm{e}}$ série. BOMSEL-HELMREICH (I 967 ), sans en faire l'objet d'un groupe particulier, signale l'existence constante de cette structure et souligne que la fragilité de ce chromosome est à l'origine du désaccord sur le nombre diploïde $2 n=38$ ou 40 ;

2 paires de petite taille à centromère médian (les I I $^{\mathbf{e}}$ et $\mathrm{I}^{\mathrm{e}}$ ).

Tout ce $\mathrm{I}^{\mathrm{er}}$ groupe a été remanié par CORNEFERT-Jensen et al. (I968). En s'appuyant sur des données biométriques, ils classent ces 12 paires de chromosomes en 3 ensembles distincts : métacentriques (3 paires), submétacentriques ( 6 paires), subtélocentriques ( 3 paires) ce qui bouleverse certains des sous-groupes précédemment décrits.

Le $2^{\mathrm{e}}$ groupe composé de $\mathrm{I} 2$ chromosomes acrocentriques est divisé d'une part en 3 paires $\left(I_{3}, I_{4}, I_{5}\right)$, dont 1'une de grande taille et les 2 autres difficiles à distinguer entre elles, d'autre part en 3 paires de taille nettement plus réduite ( $\mathbf{r} 6$, I7, I8). Ces autosomes sont les plus courts du caryotype.

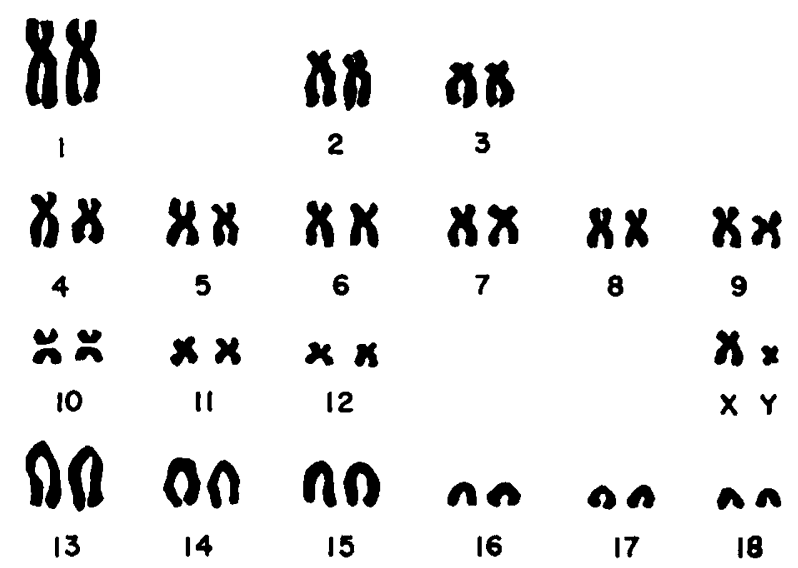

FIG. I. - Caryotype du Porc domestique - Sus scrofa domesticus - Schéma. 
b) Les hétérochromosomes. - L'hétérosome $\mathrm{X}$ est généralement identifié à un chromosome de taille moyenne. La position du centromère est controversée, médiane pour HARD et EISEN (I965), MCCONNEL et al. (I963), GERNERE (I964a), subtélocentrique pour STONE (1963), submédiane pour les autres auteurs (Evans, I965; GIMENEZ-MARTrN, I962; RUdDlE, I964; HenRicson et B̈̈CKSTRÖM, I963a; Makino, I962; MCFeEly et HARE, I966; BomSel-Hel,Mreich, I967; CoRNEFERTJENSEN et al., I968). Sa morphologie submétacentrique est précisée par des marquages radioactifs (Evans, I965), ou par biométrie (RUDDLE, I964). CORNEFERTJENSEN et al. (I968), en appliquant ces deux techniques, ont pu le détecter et ont tenté de lui attribuer un caractère de reconnaissance objectif. Toutefois, 1a très grande variabilité de longueur d'un chromosome donné, d'une métaphase à une autre, confère à ces mesures un caractère aléatoire. Ainsi, les valeurs de l'index centromérique fournies par RUDDLE (1964) et CORNEFERT-JENSEN et al. (I968) ne sont pas concordantes.

L'hétérosome $\mathrm{Y}$ est aisément reconnaissable. C'est le plus petit chromosome du caryotype, submétacentrique pour quelques auteurs et métacentrique pour les autres. STONE (I963) par contre, l'identifie à un grand submétacentrique, de taille proche de la ${ }^{\text {re }}$ paire.

\section{II. - Tests cytologiques}

Ces techniques utilisent les phénomènes de dimorphisme sexuel présenté par les noyaux interphasiques de différents types cellulaires et permettent de définir assez rapidement le sexe génétique d'un individu (tabl. 4).

TABLEAU 4

Tests cytologiques (chromatine de Barr et appendices nucléaires) chez le Porc domestique (Sus scrofa domesticus)

\begin{tabular}{|c|c|c|c|}
\hline Auteurs & Tissus & $\begin{array}{c}\text { Sexe } \\
\text { cytologique }\end{array}$ & Résultats \\
\hline SCHMIDTKE, I957 & Tissu nerveux & Corps de Barr & $\begin{array}{r}\text { of }: 73,4 \% \\
\text { o : } 3, \mathrm{x} \%\end{array}$ \\
\hline $\begin{array}{l}\text { CANTWELL, JOHNSTON, } \\
\text { ZELLER, I } 95^{8}\end{array}$ & $\begin{array}{l}\text { Tissu nerveux } \\
\text { Tissus non nerveux } \\
\text { (foie, cœur, rein, } \\
\text { thyroïde, pancréas, } \\
\text { surrénales) }\end{array}$ & $\begin{array}{l}\text { Corps de Barr } \\
\text { Corps de Barr }\end{array}$ & $\begin{array}{c}o: 95,2 \% \\
\sigma: 7,2 \% \\
\text { Nombreuses masses } \\
\text { chromatiniennes }\end{array}$ \\
\hline HOSHINO et TORYU, I959 & $\begin{array}{l}\text { Tissu nerveux } \\
\text { Tissus non nerveux } \\
\text { (surrénales, foie, } \\
\text { pancréas, rein, es- } \\
\text { tomac, intestin, } \\
\text { muscle, ovaire, uté- } \\
\text { rus) }\end{array}$ & $\begin{array}{l}\text { Corps de Barr } \\
\text { Corps de Barr }\end{array}$ & 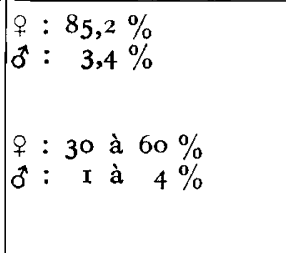 \\
\hline
\end{tabular}


TABLEAU 4 (suite)

Tests cytologiques (chromatine de Barr et appendices nucléaires) chez le Porc domestique (Sus scrofa domesticus)

\begin{tabular}{|c|c|c|c|}
\hline Auteurs & Tissus & $\begin{array}{c}\text { Sexe } \\
\text { cytologique }\end{array}$ & Résultats \\
\hline $\begin{array}{l}\text { LOCATELLI et QUARENGHI, } \\
\quad \text { I } 959\end{array}$ & Tissu sanguin & Drumsticks & $\begin{array}{l}\text { 우 }: 1 / 251 \\
\sigma: 0\end{array}$ \\
\hline KRAFT, I960 & Tissu sanguin & Drumsticks & $\begin{array}{l}q: 3 \% \text { et }+ \\
0 \text { : }: 0\end{array}$ \\
\hline LÜERS et STRUCK, I960 & Tissu sanguin & Drumsticks & $\begin{array}{l}\text { o : o à } 8 / 500 \\
\text { ô: o }\end{array}$ \\
\hline $\begin{array}{l}\text { RENTSCH, BRUCHKE et } \\
\text { SCHULZ, I960 }\end{array}$ & Tissu sanguin & Drumsticks & 오 : I à $3 / 200$ \\
\hline HAY et MOORE, I96r & Tissu nerveux & Corps de Barr & $\begin{array}{r}q: 92 \% \\
0: 6 \% \\
\end{array}$ \\
\hline HIL,BIG, I96I & Tissu sanguin & $\begin{array}{l}\text { Drumsticks } \\
\text { Sessile nodules }\end{array}$ & 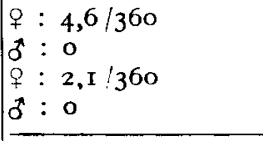 \\
\hline STRUCK, I96r & Cellules buccales & Corps de Barr & $\begin{array}{l}q: 2^{\circ} \% \\
0: 0\end{array}$ \\
\hline CoLby et CALHOUN, 1963 & Tissu sanguin & Drumsticks & 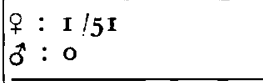 \\
\hline $\begin{array}{l}\text { WOLLRAB et LICHTNER, } \\
\text { I963 }\end{array}$ & Tissu sanguin & $\begin{array}{l}\text { Drumsticks } \\
\text { Sessile nodules }\end{array}$ & 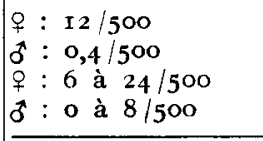 \\
\hline GERNEKE, I964a & Tissu sanguin & $\begin{array}{l}\text { Drumsticks } \\
\text { Sessile nodules }\end{array}$ & 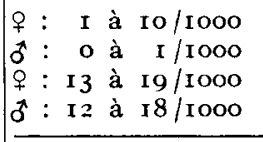 \\
\hline MEUSEL, I964 & Tissu sanguin & $\begin{array}{l}\text { Drumsticks } \\
\text { Sessile nodules }\end{array}$ & 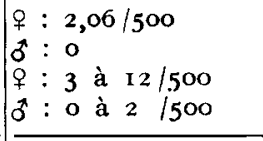 \\
\hline AXELSON, I 968 & $\begin{array}{c}\text { Embryons de } 2 \text { à } 7 \\
\text { jours }\left(\mathrm{nb}: 4^{8}\right)\end{array}$ & Corps de Barr & $\begin{array}{l}\text { 옹 nombreux } \\
\delta \text { : rares et petits }\end{array}$ \\
\hline
\end{tabular}

\section{Corpuscule de Barr.}

Cette appellation désigne la chromatine sexuelle intranucléaire découverte en I949 par BARR et BERTRAM. Cette formation trouvée chez la femelle, correspond à l'un des chromosomes $\mathrm{X}$ inactif et se présente sous forme d'une petite masse chromaffine de $I \mu$ environ de diamètre, soit libre dans le nucléoplasme, soit localisée contre la membrane du noyau ou du nucléole. 
L'apparition de la chromatine sexuelle est précoce chez le porc. AxELson (I968) la détecte dans des blastulas de 20 à 50 cellules. La meilleure définition du sexe par l'observation du corps de Barr est obtenue dans les tissus nerveux où il est présent dans environ $90 \mathrm{p}$. Ioo des cellules. Dans les autres tissus, elle est équivoque car de nombreuses masses de chromatine masquent sa présence.

\section{Appendices nucléaires des leucocytes.}

A l'étude du corps de Barr se rattache celle des appendices nucléaires découverts par Dayidson et Smith (I954) dạns des polynucléaires neutrophiles du sang. Kosenow et Scupin (I956) classent ces éléments chromaffines en 4 groupes.

$\mathrm{A}=$ appendices nucléaires pédiculés " drumsticks " mesurant environ I,5 $\mu$;

$B=$ appendices nucléaires sessiles " sessile nodules " de même taille;

$\mathrm{C}=$ petits clubs " small clubs" inférieurs à $\mathrm{I} \mu$;

$\mathrm{D}=$ raquettes " racketts " très rares.

Le rapport de ces quatre éléments serait différent chez les mâles et les femelles et offrirait donc la possibilité d'un diagnostic du sexe. Certains auteurs considèrent le rapport $=\frac{A+B}{C}$ ou simplement la somme $A+B$. D'autres s'attachent à la seule détection des "drumsticks " A, caractéristiques de la femelle, absents ou très rarement présents chez le mâle. Cet appendice est généralement considéré comme une expression du chromosome $\mathrm{X}$ mais sa fréquence n'est pas comparable à celle de la chromatine de Barr (de l'ordre de I à $3 \%$ chez la truie). La technique des frottis sanguins, séduisante par sa rapidité d'exécution, satisfait un certain nombre d'auteurs; par contre d'autres contestent son efficacité, alléguant la fréquence trop faible des drumsticks chez la femelle et leur présence parfois constatée chez le mâle.

\section{B. - Les anomalies de Sus scrofa}

Les anomalies chromosomiques des Suidae et des autres espèces domestiques n'ont généralement pas fait l'objet d'investigations approfondies.

Les animaux expulsés avant terme ou de faible viabilité ne subissent pas comme chez les humains un examen caryologique. Rien n'est tenté par les éleveurs pour les maintenir en survie et aucune enquête systématique n'est réalisée par les livres généalogiques.

Il semble que seuls les individus présentant des anomalies anatomiques génitales ou des troubles de la fertilité moins apparents, ayant une incidence sur la reproduction de l'espèce, aient fait 1'objet d'études particulières. C'est pourquoi les recherches sur l'intersexualité ont suscité le plus grand nombre de travaux. 


\section{I. - Troubles de la fertilité}

\section{L'intersexualité.}

L'intersexualité a des expressions anatomiques variées. En effet, elle peut se traduire soit par un hermaphrodisme vrai (testicule + ovaire, ou ovotestis), soit par un pseudo-hermaphrodisme femelle (ovaire), soit enfin par un pseudohermaphrodisme mâle (testicule), cette dernière forme étant la plus fréquemment rencontrée chez le Porc.

FreUdenbuRG en I968 montre que l'intersexualité atteint une fréquence de 0,002 dans la population porcine germanique. Des pourcentages plus élevés sont rapportés par CANTwELL et al., I958 (12\% environ) et par Pond et al., r96r (20\% dans des troupeaux isolés).

Les études, dont les résultats figurent dans le tableau 5 ont tout d'abord fait appel uniquement à l'observation de la chromatine sexuelle, puis, dès I962, à l'examen complémentaire du caryotype.

\section{TABLEAU 5}

Intersexualité chez le Porc domestique Sus scrofa domesticus

\begin{tabular}{|c|c|c|c|c|c|c|c|}
\hline \multirow{2}{*}{ Auteurs } & & \multirow{2}{*}{ Phénotype } & \multicolumn{2}{|c|}{$\begin{array}{l}\text { Chromatine } \\
\text { de Barr. } \\
\text { Drumsticks }\end{array}$} & \multicolumn{2}{|c|}{$\begin{array}{c}\text { Sexe } \\
\text { caryologique }\end{array}$} & \multirow{2}{*}{$\begin{array}{l}\text { Interpré- } \\
\text { tation }\end{array}$} \\
\hline & & & Tissus & Rés. & Tissus & Clirom. & \\
\hline $\begin{array}{l}\text { CANTWEI,L, } \\
\text { JONHSTON } \\
\text { et } Z \text { ELLLER } \\
\text { I958 }\end{array}$ & 4 & $\begin{array}{l}\text { pseudo ఫ̛ mâle } \\
\text { vrai } \not \\
\text { dysgénésie } \\
\text { gonadique }\end{array}$ & $\begin{array}{l}\text { tissus ner- } \\
\text { veux } \\
\text { foie, cœur, } \\
\text { rein, thyr. } \\
\text { pancréas, } \\
\text { surrénale }\end{array}$ & $\begin{array}{c}++ \\
+\end{array}$ & & & $\begin{array}{l}\text { \% génétique } \\
\text { ou syndrome } \\
\text { de Klinefelter }\end{array}$ \\
\hline $\begin{array}{l}\text { POND, ROBERTS, } \\
\text { SIMMONS, } \\
\text { I } 96 \mathrm{I}\end{array}$ & $\begin{array}{l}9 \\
I \\
6\end{array}$ & 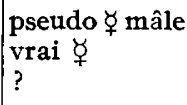 & $\begin{array}{l}\text { tissus ner- } \\
\text { veux } \\
\text { foie }\end{array}$ & +++ & & & idem \\
\hline HIL,BIG, I96r & 7 & & sang & + & & & $\begin{array}{l}69 \\
1_{0}^{\star A}\end{array}$ \\
\hline $\begin{array}{l}\text { MAKINO, SASAKI } \\
\text { SoFUNI, } \\
\text { IsHIKAWA, } \\
\text { I } 962\end{array}$ & I & pseudo ఫ̛ mâle & & & leucocytes & $\mathrm{Xx}$ & q génétique \\
\hline $\begin{array}{l}\text { HENRICSON et } \\
\text { BäCKSTRÖM, } \\
\text { I } 963 b\end{array}$ & $\mathbf{I}$ & pseudo ఫ̛ mâle & & & leucocytes & $\mathrm{xx}$ & q génétique \\
\hline GERNEKE, $1964 b$ & I & pseudo $\Varangle$ mâle & sang & + & moelle & $\mathrm{xx}$ & 7 génétique \\
\hline
\end{tabular}


TABLEAU 5 (suite)

Intersexualité chez le Porc domestique Sus scrofa domesticus

\begin{tabular}{|c|c|c|c|c|c|c|c|}
\hline \multirow{2}{*}{ Auteurs } & \multirow[b]{3}{*}{98} & \multirow{3}{*}{ 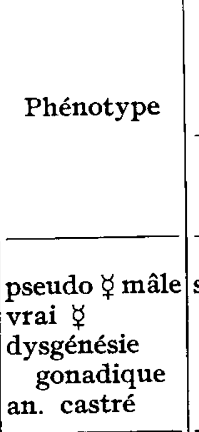 } & \multicolumn{2}{|c|}{$\begin{array}{l}\text { Chromatine } \\
\text { de Barr. } \\
\text { Drumsticks }\end{array}$} & \multicolumn{2}{|c|}{$\begin{array}{c}\text { Sexe } \\
\text { caryologique }\end{array}$} & \multirow{2}{*}{$\begin{array}{l}\text { Interpré- } \\
\text { tation }\end{array}$} \\
\hline & & & Tissus & Rés. & Tissus & Chrom. & \\
\hline MEUSEI, I964 & & & sang & $\begin{array}{c}\text { o } \\
\grave{a} \\
++\end{array}$ & & & $\begin{array}{ll}q & (40) \\
9 ? & (33) \\
0 & (25)\end{array}$ \\
\hline $\begin{array}{l}\text { HARD et EISEN, } \\
\text { I } 965\end{array}$ & I & mâle stérile & $\begin{array}{l}\text { cell. bucca- } \\
\text { les }\end{array}$ & + & $\begin{array}{l}\text { leucocytes } \\
\text { fibroblastes }\end{array}$ & $\mathrm{xx}$ & génétique \\
\hline LODJA, 1966 & $\mathrm{r}$ & pseudo ఫ̧ mâle & & & $\begin{array}{l}\text { leucocytes } \\
\text { moelle }\end{array}$ & $\mathrm{xx}$ & q génétique \\
\hline $\begin{array}{l}\text { LODJA et RUS- } \\
\text { zOVA, I } 966\end{array}$ & I & pseudo ఫ̛ mâle & & & $\begin{array}{l}\text { leucocytes } \\
\text { moelle }\end{array}$ & $\mathrm{xx}$ & q génétique \\
\hline $\begin{array}{l}\text { MCFEE, KNIGHT } \\
\text { et BANNER, } \\
\text { I } 966 \\
\end{array}$ & I & pseudo ఫ̛̣ mâle & $\begin{array}{l}\text { sang } \\
\text { autres } \\
\text { tissus }\end{array}$ & + & leucocytes & $\begin{array}{c}\mathrm{Xx} / \mathrm{XV} \\
90 \% / \\
10 \% \\
\end{array}$ & freemartin? \\
\hline VOGT, I966 & I & & & & leucocytes & $\mathrm{xx}$ & q génétique \\
\hline GERNEKE, 1967 & $\begin{array}{l}2 \\
\mathrm{I} \\
\mathrm{I} \\
3 \\
\mathrm{I}\end{array}$ & 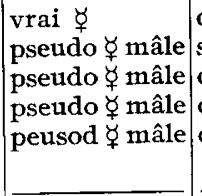 & $\begin{array}{l}\text { cell. nerv. } \\
\text { sang } \\
\text { canauxdéf. } \\
\text { cell. nerv. } \\
\text { cell. nerv. }\end{array}$ & $\begin{array}{l}+++ \\
+ \\
+++ \\
+++ \\
+++\end{array}$ & $\begin{array}{l}\text { moelle } \\
\text { moelle } \\
\text { moelle } \\
\text { moelle } \\
\text { test. rein } \\
\text { moelle }\end{array}$ & $\begin{array}{l}\mathrm{xx} \\
\mathrm{xx} \\
\mathrm{xx} \\
\mathrm{xx}\end{array}$ & $\begin{array}{l}\text { q génétique } \\
\text { Syndrome } \\
\text { adréno- } \\
\text { génital? }\end{array}$ \\
\hline $\begin{array}{l}\text { MCFEELY, HARE } \\
\text { et BIGGERS, } \\
\text { I } 967\end{array}$ & 2 & pseudo $\not$ mâle & & & $\begin{array}{l}\text { leucocytes } \\
\text { moelle } \\
\text { fibroblastes }\end{array}$ & $\mathrm{xx}$ & q génétique \\
\hline $\begin{array}{l}\text { BREEUWSMA, } \\
\text { r } 968 \\
\end{array}$ & I & pseudo $̛$ mâle & cell. nerv. & +++1 & leucocytes & $\mathrm{XXY}$ & $\begin{array}{c}\text { syndrome de } \\
\text { Klinefelter }\end{array}$ \\
\hline $\begin{array}{l}\text { BRUERE, FIEL- } \\
\text { DEN, HUT- } \\
\text { CHINGS, I968 } \\
\end{array}$ & I & pseudo $\Varangle$ mâle & cell. nerv. & +++ & leucocytes & $\mathrm{XX} / \mathrm{XY}$ & freemartin \\
\hline $\begin{array}{l}\text { GLUHOVSCHI, } \\
\text { I968 }\end{array}$ & $\begin{array}{l}8 \\
3\end{array}$ & & & & $\begin{array}{l}\text { leucocytes } \\
\text { moelle }\end{array}$ & $\underset{\mathrm{XXX}}{\mathrm{XX}}$ & $\begin{array}{l}\text { 9 génétique } \\
\text { syndrome de } \\
\text { Klinefelter } \\
\end{array}$ \\
\hline HARVEY, r968 & I & mâle & cell. nerv. & $+++\cdot 1$ & leucocytes & $\begin{array}{l}\text { XXY/ } \\
\text { XXXy } \\
60 \% / \\
17 \%\end{array}$ & $\begin{array}{l}\text { variété de } \\
\text { Klinefelter }\end{array}$ \\
\hline
\end{tabular}


TABLEAU 5 (suite)

Intersexualité chez le Porc domestique Sus scrofa domesticus

\begin{tabular}{|c|c|c|c|c|c|c|c|}
\hline \multirow{2}{*}{ Auteurs } & & \multirow{2}{*}{ Phénotype } & \multicolumn{2}{|c|}{$\begin{array}{l}\text { Chromatine } \\
\text { de Barr. } \\
\text { Drumsticks }\end{array}$} & \multicolumn{2}{|c|}{$\begin{array}{c}\text { Sexe } \\
\text { caryologique }\end{array}$} & \multirow{2}{*}{$\begin{array}{l}\text { Interpré- } \\
\text { tation }\end{array}$} \\
\hline & & & 'Tissus & Rés. & Tissus & Chrom. & \\
\hline LODJA, 1968 & I & $\begin{array}{l}\text { vrai } \Varangle \\
\text { pseudo } \Varangle \text { mâle }\end{array}$ & & & & $\begin{array}{c}\mathrm{XX} \\
\mathrm{XY} \\
\mathrm{XX} / \mathrm{XY}\end{array}$ & $\begin{array}{l}q \text { génétique } \\
\text { féminisation } \\
\text { testiculaire } \\
\text { freemartin }\end{array}$ \\
\hline $\begin{array}{l}\text { MAIK, JASKOWS- } \\
\text { KI, I } 968\end{array}$ & 25 & & & & leucocytes & $\mathrm{xx}$ & o génétique \\
\hline VOGT, I968 & $\mathbf{I}$ & pseudo $\not{\tau}$ fem. & & & leucocytes & $\begin{array}{c}\mathrm{XX} / \mathrm{XX} \\
94 \% / \\
6 \%\end{array}$ & freemartin \\
\hline $\begin{array}{l}\text { GLUHOVSCHI, } \\
\text { BISTRICEANU, } \\
\text { I969 }\end{array}$ & $15^{\circ}$ & $\begin{array}{l}\text { pseudo } \emptyset \text { mâle } \\
\text { hermaphr. } \\
\text { vrai }\end{array}$ & $\begin{array}{l}\text { cell. nerv. } \\
\text { cell. bucca- } \\
\text { les } \\
\text { cell. vagi- } \\
\text { nales }\end{array}$ & $\begin{array}{l}+++ \\
++ \\
++\end{array}$ & $\begin{array}{l}\text { leucocytes } \\
\text { moelle } \\
\text { testicule } \\
\quad \text { (embryon) } \\
\text { peau }\end{array}$ & $\begin{array}{l}\mathrm{XX} \\
\mathrm{XXY} \\
\mathrm{XY}\end{array}$ & $\begin{array}{l}\text { o génétique } \\
\text { syndrome de } \\
\text { Klinefelter } \\
\text { féminisation } \\
\text { testiculaire }\end{array}$ \\
\hline
\end{tabular}

Chromatine de Barr Drumsticks

\{ visible avec pourcentage très significatif. +++ f visible avec pourcentage non significatif. +

- La majorité des intersexués examinés à ce jour, se révèlent être des femelles génétiques bien que la plupart d'entre eux présentent un sexe gonadique typiquement mâle (testicule) ou partiellement masculinisé (ovotestis).

Un certain nombre de mécanismes expliquant l'apparition de cette dualité sont rapportés.

En général, les auteurs s'accordent à penser que ces phénomènes ont un déterminisme génétique et font 1'hypothèse d'un " gène d'intersexualité ", autosomal et récessif, qui ne s'exprimerait que chez la femelle. Parmi les interprétations les plus récentes, HAMERTon (I968) suggère le mécanisme suivant : les gènes déterminant les caractères mâles et femelles et plus précisément contrôlant la stimulation médullaire ou corticale de la gonade embryonnaire, seraient situés sur $\mathrm{X}$ et proches l'un de l'autre. $\mathrm{Y}$ agirait comme un "centre de contrôle " déclenchant chez l'individu mâle normal le fonctionnement des "gènes mâles ". HAMERTON suggère alors que chez les intersexués XX, des modificateurs autosomiques tels que le gène motte chez la Chèvre et peut-être un gène similaire chez le Porc, agirait de la même manière que le centre $\mathrm{Y}$ de contrôle, en provoquant le fonctionnement de ces gènes mâles. 
Des mécanismes plus subtils ont été proposés : translocation partielle de l'hétérosome $\mathrm{Y}$ sur le chromosome $\mathrm{X}$ au cours de la gamétogenèse mâle conduisant à un zygote à caryotype apparemment femelle, perte d'un $\mathrm{Y}$ par un zygote initialement $\mathrm{XXY}$ au cours des premières divisions de segmentation, existence d'une mosaïque $\mathrm{XX} / \mathrm{XY}$ non décelée, les cellules mâles étant trop faiblement représentées.

- Parmi ces intersexués classés en "femelles génétiques ", certains n'ont été soumis qu'au test de la chromatine de Barr. Or, la présence de masse chromatinienne ne permet pas d'exclure la possibilité d'une formule XXY analogue au Klinefelter humain comme le supposent CANTWELL et al., I955, et Pond et al., r96r. Des examens caryologiques postérieurs ont permis de vérifier parfois le bien-fondé de cette hypothèse : BREEuWSMA (I968), GLuHovschi (I968 et I969) décèlent, chez plusieurs intersexués, des caryotypes XXY à 39 chromosomes.

Par ailleurs, Harvey (rg68) met en évidence chez un mâle, possédant un système génital normal avant castration, une mosaïque sanguine $39 \mathrm{XXY} /$ 40 XXXY, confirmée par l'apparition de I ou 2 corpuscules chromatiniens dans les cellules nerveuses.

- Dans des études récentes, Lodja (I968) et Gluhovschi et Bistriceanu (1969) trouvent des formules mâles parmi leurs intersexués. Les signes pathologiques de ces animaux sont similaires à ceux du syndrome du " testicule féminisant " comme chez l'homme et le mode héréditaire semble en être dominant autosomal.

- Parfois l'existence simultanée de 2 types cellulaires, mâle et femelle, dans le sang, a été constatée (MCFEE et al., I966; BRUL̀RE et al., I968; LODJA, I968; VoGT, I968). VOGT d'une part, BRUÈRE et al. d'autre part, interprètent leurs résultats en faisant l'hypothèse de connections vasculaires intrautérines entre les jumeaux de sexe opposé. Leurs animaux, et probablement bien d'autres intersexués selon eux, seraient simplement des freemartins. Il est à noter toutefois que les anastomoses vasculaires chez le Porc ne semblent pas fréquentes (HUGHES, I929; BeNOîT, I964).

\section{Autres troubles.}

\section{a) Spermatogenèse}

Un petit nombre de travaux ont été réalisés sur la spermatogenèse (WODSEDalek, I913; KRALlinger, I93I; Crew et Koller, I939; Aparicio-Ruiz, I960).

En I963 et I964, HENRICSON et BÄCKSTRÖM ont fait une étude qualitative et quantitative comparée (description des différents types nucléaires, déroulement de la méiose et durée des différents stades) sur des testicules de verrats à fertilité normale et réduite. Ils concluent que la cause première de la stérilité est due à un prolongement statistiquement significatif de la $\mathrm{I}^{\mathrm{re}}$ ou de la $2^{\mathrm{e}}$ métaphase de 1a méiose qui aurait pour effet d'entraîner une perturbation dans la distribution des chromosomes. 
b) Un cas de translocation.

Le caryotype des cellules sanguines d'un verrat dont les portées sont réduites de 50 p. IOO (HENRICSON et BÄCKSTRÖM, I964), indique un réarrangement structural caractéristique et constant : les 3/4 d'un télocentrique sont transférés sur un petit métacentrique. C'est le seul cas de translocation hétérozygote connu jusqu'à présent.

\section{II. - Autres anomalies chromosomiques}

Elles constituent la partie la plus réduite de la cytogénétique des Suinae.

A j'exception de VOGT ( 1967 ) qui attribue un caryotype normal à 2 porcs de race Hampshire manifestant une imperforation anale et de Cimpeanu et al. (I967) qui ne détectent aucune anomalie chromosomique chez un porc méningocèle, toutes les recherches ont porté sur les embryons.

La triploïdie est fréquente chez les fœtus de truie (ThibaulT, I959; HuNTER, I967). Elle est réalisée par un mécanisme de digynie ou dispermie et intervient notamment lors de fécondations tardives. Ces œufs triploïdes sont capables d'un début de développement ( $6 \%$ de fœtus $3^{n}$ au $\mathrm{I} 7^{\mathrm{e}}$ jour) puis meurent rapidement (BOMSEL-HELMREICH, I96I). En utilisant du sperme colchiciné, HAGGQuist et BANE (I95I) et MÉLANDER (I95I) pensaient avoir obtenu des triploïdes viables, mais la formule $3^{n}$ de ces animaux n'est pas vérifiée.

MCFEELY (I968) montre que 2 à $3 \mathrm{p}$. IOo des blastocytes de Io jours sont en dégénérescence et que Io $\mathrm{p}$. Ioo environ possèdent des défauts chromosomiques : $3^{n}(\mathrm{XXX}-\mathrm{XXY}-\mathrm{XYY}), 4^{n}(\mathrm{XXYY}), 2 n / 3 n(\mathrm{XX} / \mathrm{XXX})$, ou délétion. Sachant que la mortalité embryonnaire dans la $I^{\text {re }}$ moitié de la gestation est d'environ $33 \%$ (HANLEY, I96I), il conclut qu'un tiers environ des avortements aurait une cause chromosomique.

\section{C. - Sus scrofa $L$.}

Des examens chromosomiques ont été réalisés sur une race locale de porcs sauvages européens (sanglier) (MCFEE et al., I966; RARY et al., I968). Des cultures leucocytaires montrent la présence chez le mâle comme chez la femelle d'un nombre diploïde de 36 ou 37 (tabl. 6).

Chez les animaux à 36 chromosomes, l'appariement en I 8 couples est aisé. Une paire de submétacentriques remplace ainsi 2 paires de télocentriques par rapport à Sus scrofa domesticus. Chez les individus à 37 chromosomes, un submétacentrique se substituerait à 2 télocentriques non homologues.

Les produits de croisements variés entre des animaux à 36,37 et 38 chromosomes sont tous fertiles (MCFEE et BANNER, I969). Ces hybridations réussies jointes aux observations caryologiques suggèrent que le matériel héréditaire a subi un simple remaniement morphologique (polymorphisme chromosomique). Dans ces conditions des individus à nombre impair de chromosomes ont donc une méiose impliquant l'apparition d'un trivalent et conduisant à des gamètes fonctionnels. En terme de phylogénèse, la race domestique serait issue de la race sauvage par l'éclatement centrique d'une paire de chromosomes submétacentriques. 
TABLEAU 6

Rappel de la formule chromosomique de différents Suinae à l'exclusion du Porc domestique Sus scrofa domesticus

\begin{tabular}{|c|c|c|c|c|c|}
\hline Classification & Tissus & $2 n$ & $\mathbf{x}$ & $\mathbf{Y}$ & Auteurs \\
\hline \multicolumn{6}{|l|}{ FAMILIE DES SUIDAE } \\
\hline Dicotyles tajacu. . . . & testicule & 30 & ? & $?$ & KRALIINGER，I936 \\
\hline Dicotyles angulatus . . & testicule & 30 & ? & ? & $\begin{array}{l}\text { SPALDING et BERRY, } \\
\text { I956 }\end{array}$ \\
\hline Sus vitattus leucomystax & $\begin{array}{l}\text { testicule } \\
\text { leucocytes }\end{array}$ & $\begin{array}{l}40 \\
3^{8}\end{array}$ & $\underset{\text { SM }}{\mathbf{X}}$ & $\begin{array}{c}\mathbf{Y} \\
\mathbf{M} \\
\text { (petit) }\end{array}$ & $\begin{array}{l}\text { MAKINO, I946 } \\
\text { MURAMOTO, MAKI- } \\
\text { NO, ISHIKAWA, } \\
\text { KANAGAWA, I965 }\end{array}$ \\
\hline Sus scrofa L. $\left({ }^{*}\right)$. . . & leucocytes & 36 & SM & $\mathbf{M}$ & $\begin{array}{l}\text { MCFEE, BANNER et } \\
\text { RARY, I } 966\end{array}$ \\
\hline $\begin{array}{c}\text { Hybride (Sus scrofa } L{ }^{*} \\
\times \text { Sus scrofa domesti- } \\
c u s \text { ).......... }\end{array}$ & leucocytes & 37 & $\mathrm{SM}$ & $\mathbf{M}$ & $\begin{array}{l}\text { RARY, VERNON, } \\
\text { MATSCHKE, et } \\
\text { MURPHREE, I } 968\end{array}$ \\
\hline \multicolumn{6}{|l|}{$\begin{array}{l}\text { FAMIIE DES HIPPO- } \\
\quad P O T A M I D A E\end{array}$} \\
\hline $\begin{array}{l}\text { Hippopotamus amphi- } \\
\text { bius L.. . . . . . }\end{array}$ & moelle & 36 & $\underset{\text { (moyen) }}{\mathrm{SM}}$ & $\underset{\text { (petit) }}{\mathrm{SM}}$ & GERNEKE, I965 \\
\hline
\end{tabular}

* Lignée de Sangliers (European wild swine) élevée dans une réserve du Tennessee.

\section{D. - Sus Vittatus Leucomystax}

Une Ire étude histologique de testicule (MAKINO, I946) attribue à cette espèce 40 chromosomes. L'utilisation de techniques modernes de cultures sanguines (Muramoto et al., I965) conduit à la définition d'un caryotype à 38 chromosomes, analogue à celui du Porc domestique (tabl. 6).

\section{SOUS-FAMILE DES DICOTYLINAE}

\section{A. - Dicotyles Tajacu}

KRALLINGER (I936) caractérise cette espèce par le nombre $2 n=30$ à partir des résultats d'un examen histologique de testicule (tabl. 6).

La description du caryotype est brève : 2 grandes paires de chromosomes, l'une métacentrique, l'autre submétacentrique et I3 paires de plus petite taille et de longueur décroissante. Il n'identifie pas les hétérochromosomes. 


\section{B. - Dicotyles angulatus}

Des squashes de tissu testiculaire, réalisés sur une espèce très voisine, sinon identique à la précédente (SPALDING et BERRY, I956) mettent également en évidence un nombre chromosomique de $2 n=30$ (tabl. 6).

Les chromosomes peuvent être classés en 4 groupes : 2 grands métacentriques, 2 grands submétacentriques, I 2 métacentriques, beaucoup plus petits, I4 punctiformes. Les chromosomes sexuels ne sont pas identifiés.

Il faut noter que les examens caryologiques consacrés au genre Dicotyles sont déjà anciens et que l'application des techniques modernes de cultures cellulaires à ces mêmes animaux permettrait 1'acquisition d'informations plus précises.

\section{FAMILIE DES HIPPOPOTAMIDAE}

\section{Hippopotamus amphibius}

Cette espèce a fait 1'objet d'une seule étude. Un examen cytologique montre la présence de drumsticks dans 64 p. Ioo des polynucléaires neutrophiles à caryotype femelle. Chez le mâle, de petites formations vacuolaires sont détectables, dues peut-être à des artefacts (GERNEKE, r965).

Le nombre chromosomique de l'espèce, déterminé sur cellules de moelle osseuse, est de 36 chromosomes non télocentriques (tab1. 6). Leur subdivision en 4 groupes tient compte de la longueur et de l'estimation de l'index centromérique.

Les centromères de l'hétérosome $\mathrm{X}$, de taille moyenne, et de l'hétérosome $\mathrm{Y}$, le plus petit du caryotype, sont submédians.

\section{CONCLUSION}

Cette revue montre la carence des travaux caryologiques consacrés aux Suiformes autres que Sus scrofa domesticus $L$. Afin de faciliter l'établissement de la phylogenèse de ce sous-ordre, l'extension des investigations aux autres espèces est particulièrement souhaitable.

En ce qui concerne Sus scrofa domesticus, son caryotype, maintenant bien connu, autorise des recherches s'apparentant à celles conduites en cytogénétique humaine.

Reçu pour publication en novembre 1969.

\section{REMERCIEMENTS}

Nous tenons à remercier $\mathrm{M}^{\mathrm{me}} \mathrm{O}$. Bomsel-Helmpeich et M. P.-C. Popescu dont les remarques nous ont été précieuses. 


\section{SUMMARY}

\section{THE CHROMOSOMES OF SUIFORMS}

All the documents devoted to chromosomic examination of Suiforms (Table 1), and especially those of the domestic pig, are reviewed in this memorandum. The normal animal is characterized by 38 chromosomes, a number recognized rather late (1960) (Table 3) because of the utilization of cellular structures (Table 2). The karyotype (Fig. 1) includes 12 pairs of centromere chromosomes approximately submetacentric or metacentric, and 6 pairs of terminal centromere chromosomes. The medium size, submetacentric $\mathrm{X}$ heterosome has been clearly identified by autoradiography. The metacentric or submetacentric $Y$ heterosome is the smallest element in the karyotype. Cytological tests (Table 4) have also been used to determine the genetic sex. Barr's chromatin, detected precociously (20-cell blastulas), is present in 90 per cent of the nervous cells of the trout. The hematological technique is based on observation of different types of nuclear appendices (drumsticks, sessile nodules) which the polymorphonuclear neutrophils present. This technique is very widely used, and gives results which are rapid but discutable.

Chromosomic anomalies in the pig have not been thoroughly studied, and karyological research almost exclusively concerns fertility disorders.

The rather frequent intersexuality (Table 5) found in this species (up to $20 \%$ ) is expressed anatomically in various ways (true hermaphrodism, male and female pseudo-hermaphrodism). A large number of intersexual animals have an XX karyotype, and most authors assume that an autosomal, intersexual gene, with recessive action limited to the female sex, is responsible for the anomaly. Some XY animals present pathological signs similar to those of " testicular feminization", which is dominant and hereditary. Other intersexual individuals have a 39 chromosome karyotype, and a XXY sex formula which resembles Klinefelter's syndrome of man. Lastly, some chimeric XX /XY blood formulas have been found which are attributed to freemartinism.

Studies concern other sexual disorders such as translocation accompanied by semi-fertility, and several cases of disordered spermatogenesis in the boar.

Also, triploidy is frequent in foetuses and is lethal. Aberrant formulas $(4 n, 2 n / 3 n$, deletion), said to be the origin of some miscarriages, have been discovered in blastocytes.

All research done on Suiforms other than Sus scrofa domesticus L., only concerns determination of the chromosome number (Table 6), and possibly establishment of the karyotype:

- Sus scrofa domesticus $L .: 2 n=36$ or 37 . Products of crossings between 36,37 , or 38chromosome animals are fertile. This chromosomic polymorphism is due to centric rupture.

- Dicotyles tajacu: $2 n=30$.

- Hippopotamus amphibius: $2 n=36$.

A study of this inventory makes clear two possible methods of research: one consists in establishing the Suiform chromosome number for phylogenetic purposes; the object of the other would be to make karyologic analyses for Sus scrofa domesticus $L$. homologous to those done for man.

\section{RÉFÉRENCES BIBLIOGRAPHIQUES}

ANTonio E., I964. Il cariogramma del Suino. Veter. ital., 15, 925-933.

Antonio E., CAstrucci G., I964. I-Cromosomi del Suino. Atti Soc. ital. Sci. veter., 18, 723-727.

ApARIcio RuIz D., 1960. Estudio citogenetico de la espermatogenesis en el cerdo. Archos Zootecnia, 9, I03-r3i.

Axelson M., x968. Sex chromatin in early pig embryos., Hereditas, 60, 347-354.

Benoîr, R. I964. Quelques considérations sur l'hermaphrodisme. Schweiz. Arch. Tierheilkde, 106, 63-73.

BOMSEL-Helmreich O., I96I. Hétéroploïdie expérimentale chez la truie, IV. Internation. Congr. Anim. Reprod., 1, I-4.

Bomsel-HelmRerch O., r967. Triplö̈die expérimentale chez quelques Mammifères. Thèse de Doctorat d'État ès-Sciences naturelles. Faculté des Sciences de Paris, I 2 pp.

Bomsel-Helmretch O., ThIBAUlt C., 1967. Anomalies chromosomiques et troubles pathologiques ou sexuels chez les Mammifètes. Ann. Biol., 6, 287-322.

BReeuwsMa A. J., I968. A case of XXY sex chromosome constitution in an intersex pig. J. Reproduct. Fertil., 16, II9-120.

BRUìre A. N., Fielden E. D., Hutchings H., 1968. XX/XY mosaicism in lymphocyte cultures from a pig with freemartin characteristics. New. Zeal. veter. J., 16, 3I-38.

BruYère P., I966. Microméthode de culture et de marquage des cellules sanguines chez les animaux domestiques. Ann. Méd. véter., 110, $201-208$. 
Bryden W., 1933. The chromosomes of the pig. Cytologia, 5, 149-153.

Campeanu C., Campeanu N., Iliescu I., 1967. Cariotipul la porc cu meningocel. Revta Zooteh. Med. veter., 1, 68-74.

Cantwell G. E., Johnston E. F., Zeller J. H., I958. The sex chromatin of swine intersexes. J. Hered., 49, 199-202.

Colby E. B., CalHoun L., 1963. Accessory nuclear lobule on the polymorphonuclear neutrophil leucocyte of domestic animals. Acta cytol., 7, 346-350.

Cornefert-Jensen Fr., HARE W.-C.-D., ABT D. A., I968. Identification of the sex chromosome of the domestic pig., J. Hered., 59, 25 I-255.

Crew F. A. F., Koller P. C., 1939. Cytogenetical analysis of the chromosomes in the pig. Proc. R. Soc. Edinb., 59, I63-175.

EvaNs H. J., r965. A simple microtechnique for obtaining human chromosome preparations with some commerts on DNA replication in sex chromosome of the Goat, Cow and Pig. Exper. Cell. Res., 38, 5 II-5I6.

Frechrop S., 1955. Sous-ordre des Suiformes, in Grassé. Traité de Zoologie, 17, 509-535. Masson, Paris.

FreUdenduRG F., I958. Die Bedeutung der Intersexualität beim Schwein als erbliche Geschlechtsmissbildung. Mh. Vet. Med., Leipzig, 13, 608.

GERNEKE W. H., I964a. The karyotype and neutrophil nuclear appendages of the pig (Sus scrofa domesticus). S. Afr. J. Sci., 60, 373-376.

GERNEKE W. H., r964b. The karyotype of a gonadal male pig intersex. S. Afr. J. Sci., 60, 347-352.

GERNEkE IV. H., I965. The chromosomes and neutrophil nuclear appendages of Hippopotamus Amphibius Linnaeus 1758. Onderstepoort J. veter. Res., 32, I81-186.

Gerneke W. H., 1966. Cytogenetics and its replications in veterinary medicine. J. S. Afr. vet. med. Ass., 37, 466-472.

GERNEKE W. H., I967. Cytogenetic investigations on normal and malformed animals, with special reference to intersexes. Onderstepoort $J$. veter. Res., 34 219.299.

Gimenez-Martin G,. Lopez-SaEz J. F. I962. Dotaciones cromosomicas en los Mamiferos domesticos (nota preliminar). Genet. iber., 14 7-17.

Grmenez-Martin G., Lopez-Saez J. F. r966. Cromosomas de Mamiferos domesticos. Genet. iber., 18, I-I 27.

Gimenez-Martin G., Lopez-Saez J. F., Monge E. G. 1963. Somatic chromosomes of the pig. J. Hered., 53,281 .

Gluhovschi N., Bistriceanu M., Rosu M., Bratu M., I968. Contributions to the study of chromosomal aspects in some reproduction troubles of domestic animals. VI int. Congr. anim. Reprod., 2, 881-883.

Gluhovschi N., Bistriceanu M., I969. Cytogenetic researches on swine intersexuality. Revta Zooteh. Med. Vet., 19, 52-57.

Goldman I. L., Dobrianov D. S., Karlinov D. V., I968. Les chromosomes chez le porc. Svinovodstvo, 22, 29-30.

HäGGQvist G., BANE A., I951. Kolchizininduzierte Heteroploidie beim Schwein. Kgl. svenska Vetenskapsakad. Handl. Série 4, 3, I-I4.

Hamerton J. I., 1968. Significance of sex chromosome derived heterochromatin in Mammals. Naturi, 219, 9 ro-914.

HANce R. T., r917. The diploid chromosome complexes of the pig (Sus scrofa) and their variations. J. Morphol., 30, I55-202.

HaNce R. T., I918. Variations in somatic chromosomes. Biol. Bull., 35, 33-37.

Hanley S., I96r. Prenatal mortality in farm animals. J. Reprod. Fert., 2, r82.

HARD W. L., EISEN J. D., 1965. A phenotypic male swine with a female karyotype. J. Hered., 56 , 255-258.

HARvey M. J. A., I968. A male pig with an XXY / XXXY sex chromosome complement. J. Reprod. Fert., 17, 319-324.

HAY J. C., MOORE K. L., I96r. The sex chromatin in various mammals. Acta anat., 45, 289-309.

Henricson B., BÄckströ̀ L., 1963a. Spermatocytogenesis in the boar. Acta anat., 53, $276-288$.

Henricson B., Bäckströм L., 1963b. The karyotype of normal pigs and of one intersex. XI int. Conf. Genet., 1, 137.

Henricson B., BÄCKSTRÖm L., I964a. A systematic study of the meiotic divisions in normal and subfertile or sterile boars and bulls. J. Reprod. Fert., 7, 53-64.

Henricson B., BÄckström I., I964b. Translocation heterozygosity in a boar. Hereditas, 52, x66-I7o.

HIIBIG S., I96r. Hämotologische Geschlechtsdiagnose an männlichen, weiblichen und intersexen Haussschweinen. Arch. Tierzucht., 4, 343-349.

HILLEBRAND P., 1936. Untersuchungen über die Chromosomem bei drei verschieden Rassen von Hausschweinen. Diss. Friedrich Wilhelms Univ., Breslau.

Hoshrno T., ToRYU Y., 1959. Sex chromatin in domestic animals. Tohoku J. agric. Res., 4, II3-I25. 
Hsu T. C., Benirschke K., 1967. An atlas of mammalian chromosomes. 1, Springer Verlag, NewYork.

Hugues W., 1929. The freemartin condition in swine. Anat. Rec., 41, 213-245.

Hunter R. H. E., I967. The effects of delayed insemination on fertilization and early cleavage in the pig. J. Reprod. Fert., 13, I33-147.

Johnston E. F., Zeller J. H., Cantwell G., 1958. Sex anomalies in swine. J. Hered., 49, $255^{-26}$.

Kosenow W., Scupin H., r956. Die Bestimmung des Geschlechts mit Hilfe einer Kernerhangsformel der leukozyten. Acta Haematol., 15, 349.

KRAFT H., 1960. Ueber das Geschlechtschromatin am Ruhekern von Leukozyten der Säugetiere. Blut, 6, 18.

KRALliNGer H. F., I93I. Cytologische Studien and einigen Haussäugetieren. Arch. Tiernähr. Tierzucht., 5, 127-1 87.

Krallinger H. F., I936. Die Chromosomen des Halsbandpekaris. Z. Zellforsch. mikrosk. Anat., 24, I-IO.

Lodja L., 1966. The use of a Cytogenetical Method in the Study of Congenital Anomalies in Animals (tcheque, rés. angl., all.). Vet. Med., Praha, 11, 467-471.

LodJA L., 1968. Das chromosomale Bild des testikulären Hermaphroditismus bei Schweinen und die Erblichkeit dieser Störung. VI int. Congr. anim. Reprod., 2, 897-899.

Lojda I.., RUszova M., I966. Das Chromosenbild beim testikulären Hermaphroditismus des Schweines. Fortpfl. Besam. Haustiere, 2, 374-382.

LüERS Th., STRUCK E., r96o. Untersuchungen zur geschlechts-spezifischen Struktur der Neutrophilenkerne bei einigen Haustieren (Ziege, Schaf, Schwein, unter Berücksichtigung der Zwitter). Zool. Anz., 164, 89-103.

McConnell J., Fechreimer N. S., Grlmore L. O., r963. Somatic chromosomes of the domestic pig. J. anim. Sci., 22, 374-379.

MCFee A. F., BANNeR M. W., 1969. Inheritance of chromosome number in pigs. J. Reprod. Fert., 18, 9-14.

MCFeE A. F., Banner M. W., Rary J. M., 1966. Variation in chromosome number among European wild pigs. Cytogenetics, $5,75-8 \mathrm{r}$.

MCFeE A. F., KNight M., BANner M. W., I966. An intersex pig with XX/XY leucocytes mosaicism. Canad. J. Genet. Cytol., 8, 502-505.

MCFeeny R. A., I966. A direct method for the display of chromosomes from early pig embryos. $J$. Reprod. Fert., 11, I6I-163.

MCFeely R. A., 1967. Chromosome abnormalities in early embryos of the pig. J. Reprod. Fert., 13, 579-582.

MCFeEly R. A., HARE W. C. D., I966. Cytogenetic studies of the domestic pig. In I. K. Bustad Swine in biomedical research, 13-24. Frayne Printing, Seattle.

MCFEely R. A., HARE W. C. D., BIGgers J. D., 1967. Chromosome studies in I4 cases of Intersex in domestic mammals. Cytogenetics, 6, 242-253.

MaIK H., JASkowski L., r968. Chromosome sex determination of intersexual pigs (Sus scrofa domesticus). VI int. Congr. anim. Reprod., 2, 909-9rI.

Makino S., 1944a. Chromosome studies in domestic Mammals. III-The chromosome complex of the pig (Sus scrofa). Cytologia, 13, x70-178.

Makmo S., 1944b. A contribution to the study of the chromosomes of domestic Mammals. Zool. Mag., 56, 8-15.

Makibo S., 1946. On the karyological relationship of the domestic swine and Japanese wild boar (jap., rés. angl.). Kromosomo, 1, 12-17.

Makino S., 1949. A review on the chromosomes of domestic mammals. Jap. J. Zootech. Sci., 19, 5-I5.

Makino S., I95I. An atlas of the chromosome numbers in animals. Iowa State College Press, Ames, Iowa, and ed., $282-284$.

MAkno S., 1956. A review of the chromosome numbers in animals. Hokuryukan, Tokyo, I75-177; $298-299$.

Makino S., SaSakr M. S., Sofunie T., Ishikawa T., 1962. Chromosome condition of an Intersex swine. Proc. Japan Acad., 38, 686-689.

Melander Y., r95r. Polyploidy after colchicine treatment of pigs. Hereditas, 37, 288-289.

MeUSEL H., I964. Blutmorphologische Untersuchungen auf geschlechtsspezifische kernanhänge an den neutrophilen granulozyten bei schweinezwittern. Diss. Vet. Med., Humbolt Univ. Berlin.

Muramoto J., Makino S., Ishikawa T., Kanagawa H., r965. On the chromosomes of the wild boar and the boar-pig hybrids. Proc. Japan Acad., 41, 236-239.

Pond W. G., RoBerts S. J., Smmons K. R., I96r. True and pseudohermaphroditism in swine herd. Cornell Vet., 51, 394-404.

QuARenghi F., Locatelil A., 1959. Sur la présence de " drumstick " selon Davidson et Smith, dans le noyau des leucocytes polynucléaires neutrophiles chez différentes espèces d'animaux. XVI internation. vet. Congr., 2, 895-896. 
Rary J. M., Henry V. G., Matschke G. H., Murphrfe R. L., r968. The cytogenetics of swine in the Tellico Wildlife Management area, Tennessee. J. Hered., 59, $201-204$.

Rentsch K. J., BRUSchKe G., Schulz F. H., r960. Ueber morphologische Geschlechtsunterschiede an den Kernen von neutrophilen Granulozyten bei Tieren. Dische Gesundh. Wes., 15, 240-243.

RUDDlE F. H., I96r. Chromosome variation in cell populations derived from pig kidney. Cancer Res., 21, $885-894$.

RUDDLE F. H., r964. Quantitation and automation of chromosomal data with special reference to the chromosomes of the Hamshire pig (Sus scrofa). In R. J. C. HARRIs, Cytogenetics of cells in culture, 273-305, Academic Press, New-York.

SACHS L., 1954. Chromosome numbers and experimental polyploidy in the pig. J. Hered., 45, 2 I-24.

Schмmтke C., 1957. Ueber die karyologische Geschlechtsdifferenzierung bei Tieren. Z. Tierzücht. Zücht-Biol., 70, $203-232$.

Spalding J. F., Berry R. O., 1956. Chromosome study of the wild pig (Pecari angulatus) and the domestic pig (Sus scrofa). Cytologia, 21, 81-84.

Stone L. E., r 963 . A chromosome analysis of the domestic pig (Sus scrofa) utilizing a peripheral-blood culture technique. Canad., J. Genet. Cytol., 5, 38-42.

STRUCK E., I96x. Vergleichende Untersuchungen iiber das "geschlechtschromatin " bei einigen haustieren mit Hilfe des Buccaltests. Z. Zellforsch. mikrosk. Anat., 55, 662-672.

Thrbault C., r959. Analyse de la fécondation de l'œuf de la truie après accouplement ou insémination artificielle. Ann. Zootech., 8, suppl. I65-177.

VoGt D. W., 1966. Cytological observations on an intersex pig. J. anim. Sci., 25, 252 (abstract).

VoGT D. W., r967. Chromosome condition of two atresia ani pigs. J. anim. Sci., 26, roo2-1004.

VoGr D. W., r968. Sex chromosome mosaicism in a swine intersex. J. Hered., 59, I66-167.

Wodsedalex J. E., r913. Spermatogenesis of the pig with special reference to the accessory chromosomes. Biol. Bull., 25, 8-32.

Wollrab J., Lichtner T., r963. Ueber die chromosomale Geschlechts-bestimmung bei Haustieren und das verhalten geschlechtssepzifischer Neutrophilenkernanhänge bei normalgeschlechtlichen, kryptorchen und intersexen Schweinen. Zuchthyg., Fortpfl. Stör. Besam. Haustiere, 7, $24 \mathrm{I}-253$. 